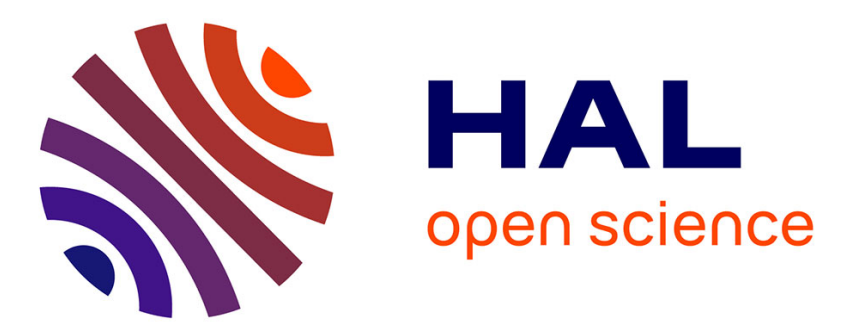

\title{
A real-time acquisition system for pump-probe spectroscopy
}

Paolo Bartolini, Roberto Eramo, Andrea Taschin, Marco de Pas, Renato Torre

\section{To cite this version:}

Paolo Bartolini, Roberto Eramo, Andrea Taschin, Marco de Pas, Renato Torre. A real-time acquisition system for pump-probe spectroscopy. Philosophical Magazine, 2007, 87 (3-5), pp.731-740. 10.1080/14786430600953780 . hal-00513766

\section{HAL Id: hal-00513766 https://hal.science/hal-00513766}

Submitted on 1 Sep 2010

HAL is a multi-disciplinary open access archive for the deposit and dissemination of scientific research documents, whether they are published or not. The documents may come from teaching and research institutions in France or abroad, or from public or private research centers.
L'archive ouverte pluridisciplinaire HAL, est destinée au dépôt et à la diffusion de documents scientifiques de niveau recherche, publiés ou non, émanant des établissements d'enseignement et de recherche français ou étrangers, des laboratoires publics ou privés. 


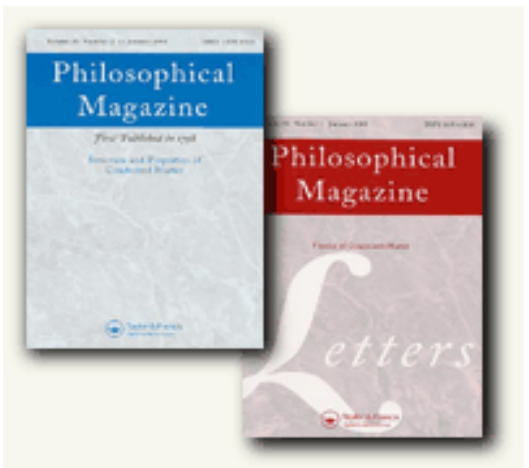

\section{A real-time acquisition system for pump-probe spectroscopy}

\begin{tabular}{|c|c|}
\hline Journal: & Philosophical Magazine \& Philosophical Magazine Letters \\
\hline Manuscript ID: & TPHM-06-Мay-0154.R1 \\
\hline Journal Selection: & Philosophical Magazine \\
\hline $\begin{array}{l}\text { Date Submitted by the } \\
\text { Author: }\end{array}$ & 03-Jul-2006 \\
\hline Complete List of Authors: & $\begin{array}{l}\text { Bartolini, Paolo; LENS, Universita' di Firenze } \\
\text { Eramo, Roberto; LENS, Universita' di Firenze } \\
\text { Taschin, Andrea; LENS, Università di Firenze } \\
\text { De Pas, Marco; LENS, Universita' di Firenze } \\
\text { Torre, Renato; LENS, Universita' di Firenze }\end{array}$ \\
\hline Keywords: & liquids, optical spectroscopy \\
\hline Keywords (user supplied): & time resolved, kerr effect, rapid scan \\
\hline \multicolumn{2}{|c|}{$\begin{array}{l}\text { Note: The following files were submitted by the author for peer review, but cannot be converted } \\
\text { to PDF. You must view these files (e.g. movies) online. }\end{array}$} \\
\hline Kerr05.tex & \\
\hline
\end{tabular}

\section{S) ScholaroNE \\ Manuscript Central}




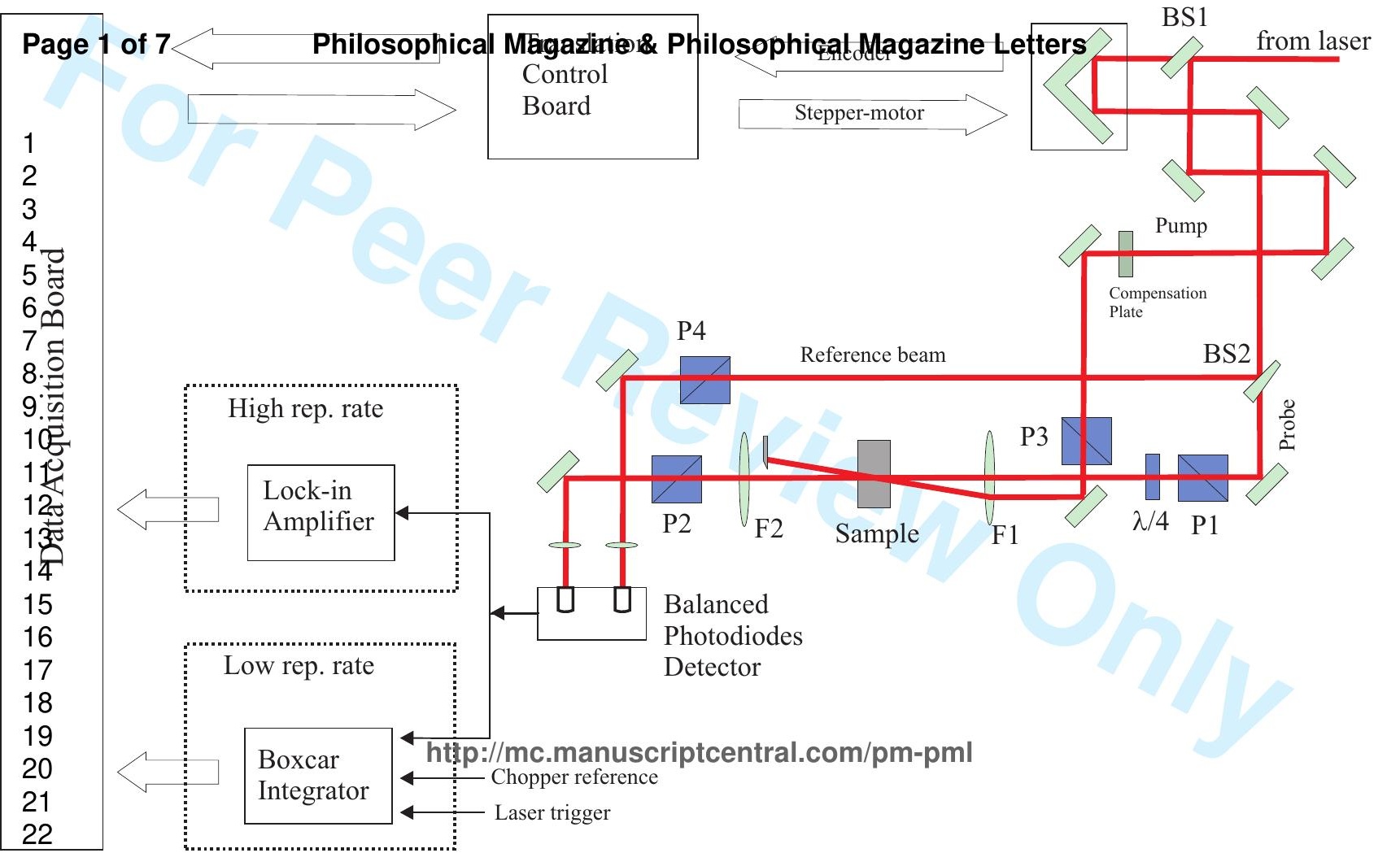




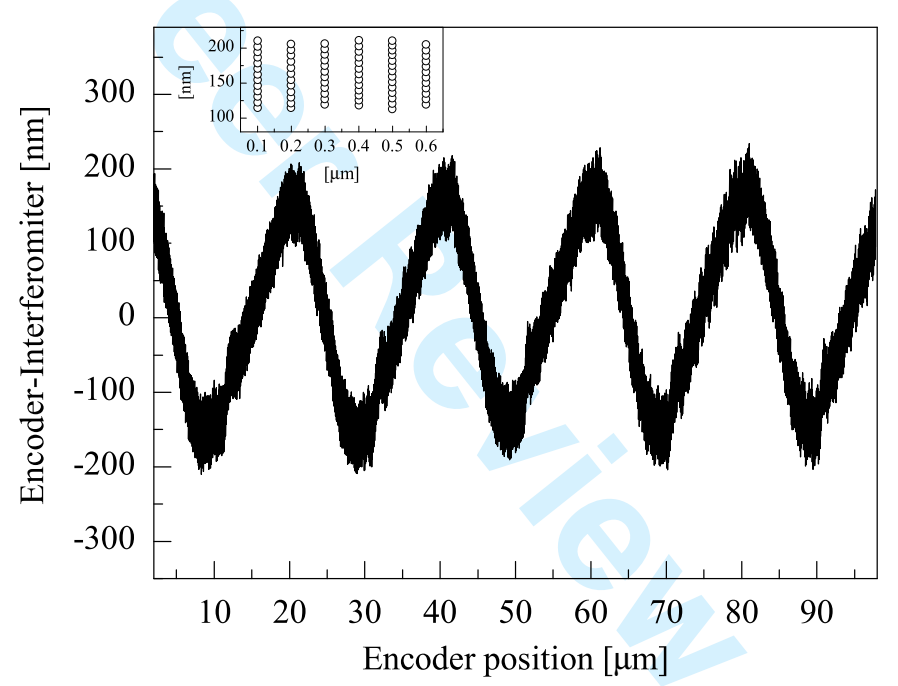




1
2
3
4
5
6
7
8
9
10
11
12
13
14
15
16
17
18
19
20
21
22
23
24
25
26
27
28
29
30
31
32
33
34
35
36
37
38
39
40
41
42
43
40
45
49
50
51
52
53
55
50

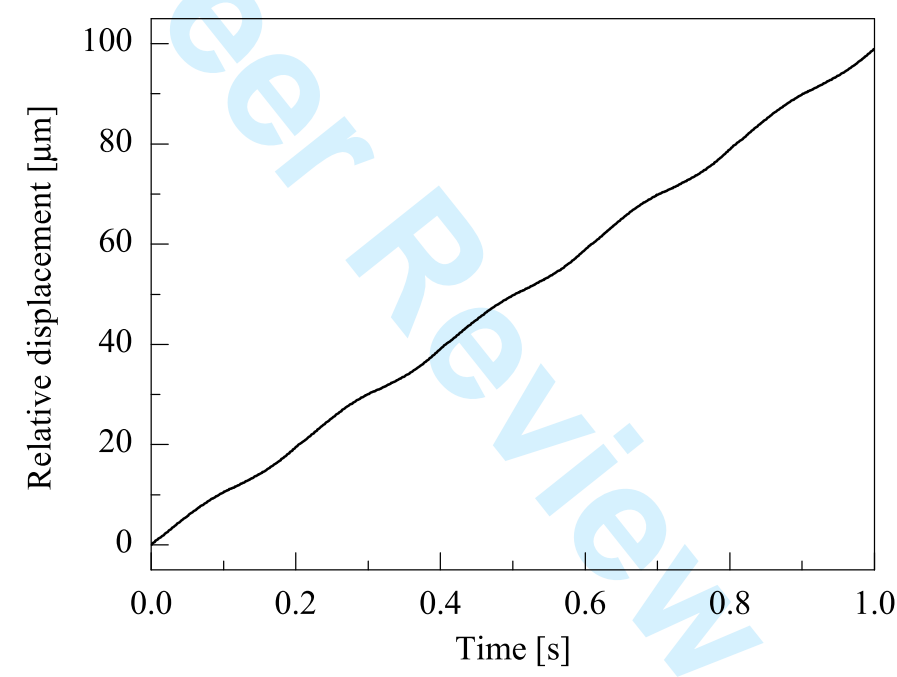

http://mc.manuscriptcentral.com/pm-pml 

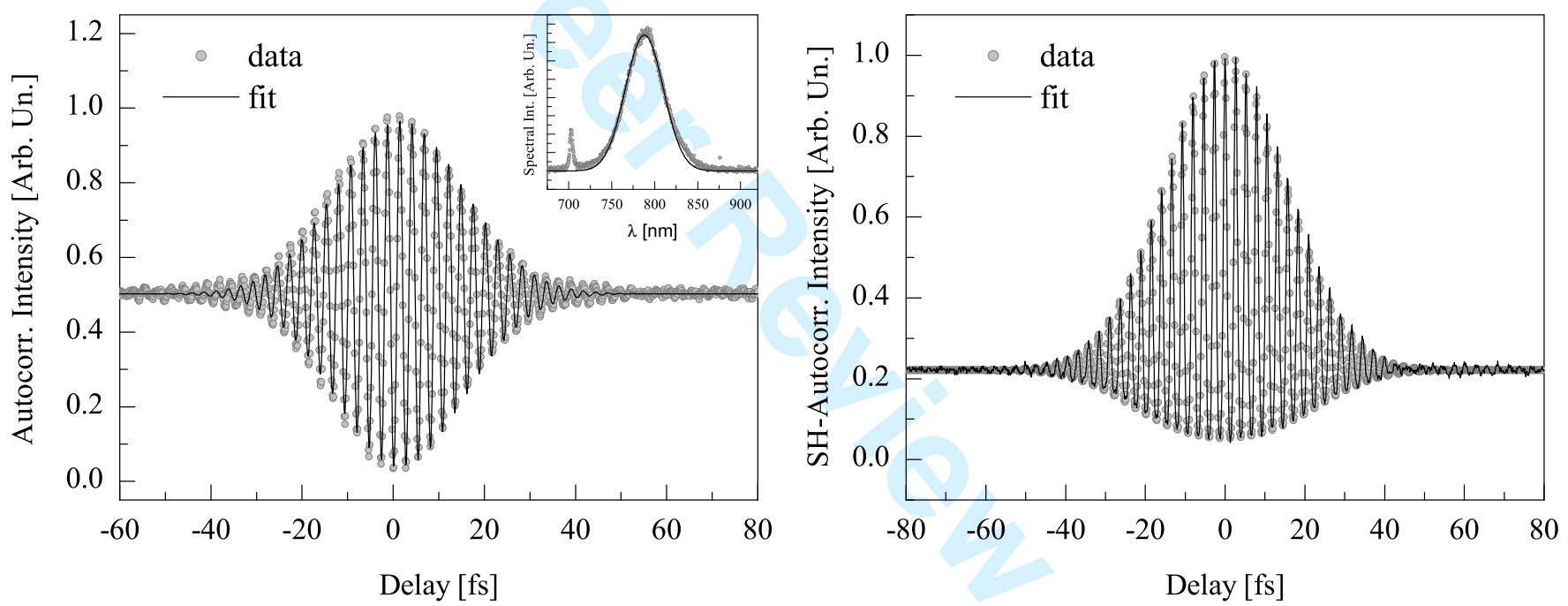


1
2
3
4
5
6
7
8
9
10
11
12
13
14
15
16
17
18
19
20
21
22
23
24
25
26
27
28
29
30
31
32
33
34
35
36
37
38
39
40
41
42
43
40
45
49
50
51
52
53
55
50

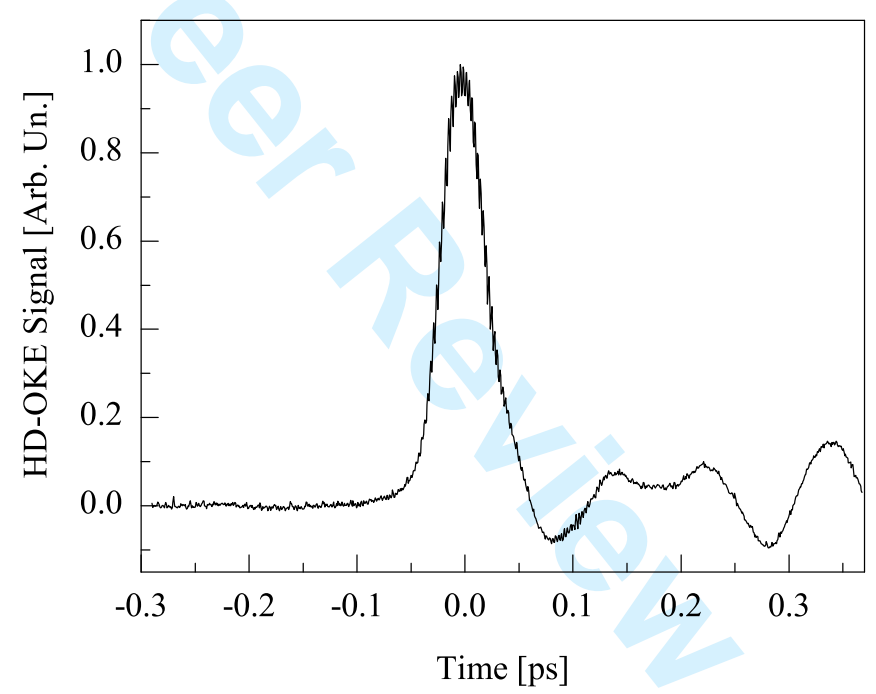

http://mc.manuscriptcentral.com/pm-pml 


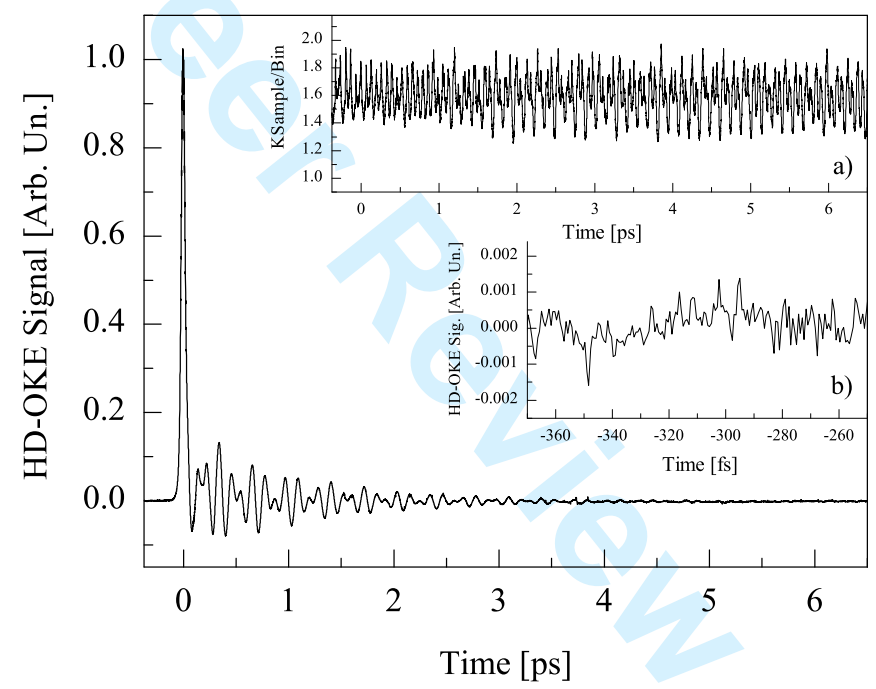

http://mc.manuscriptcentral.com/pm-pml 
1

2

3

4

5

6

7

8

9

10

11

12

13

14

15

16

17

18

19

20

21

22

23

24

25

26

27

28

29

30

31

32

33

34

35

36

37

38

39

40

41

42

43

44

45

46

47

48

49

50

51

52

53

54

55

56

57

58

59

60

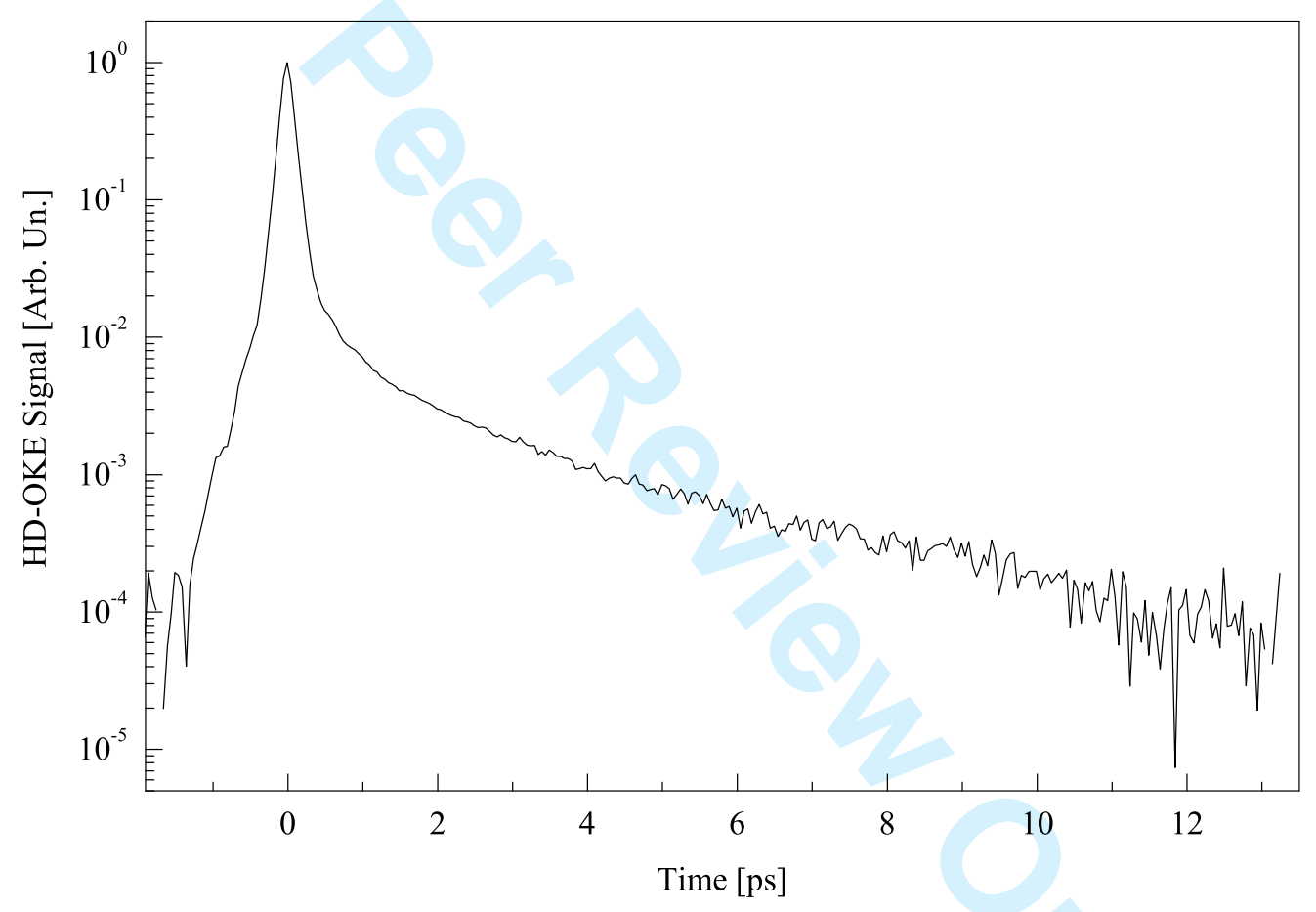

http://mc.manuscriptcentral.com/pm-pml 